\title{
Web-Based Collaborative Learning: A proposed Learning Platform for the School of ICT, Auchi Polytechnic
}

\author{
Momodu Mustapha, Kanoba Idris Isah and Obeten, Michael Okoi \\ Department of Computer Science, School of Information and Communication Technology. Auchi Polytechnic, \\ Auchi, Edo State \\ musty1428@gmail.com
}

\begin{abstract}
Technological advancements in the World Wide Web continue to gain widespread adoption, with various kinds of applications finding their use in education, including those for 'digital collaboration'. The term has become widely known for its extension of our traditional means of distributed learning and workflow. In present-day Nigeria, collaboration between students and educators in most tertiary institutions still involves the most basic use of instant messaging tools provided via online chat forums, google groups, WhatsApp, for knowledge sharing over the internet. However, these tools come with their limitations. Take 'Yahoo' and 'google' groups for example; yahoo groups are meant solely for students possessing yahoo mail accounts, and the same applies for google groups. Overall, the user-access convention on these platforms makes it difficult for students to enjoy any cross-platform privileges in the absence of email ownership on the particular service domain. Owing to this, our research project sought to bridge this identified gap, with a pilot project in the School of ICT, Federal Polytechnic, Auchi. We proposed the development and implementation of this unified platform to meet the salient and underlying collaborative need within our learning community. The system (PolyCollab) is a cross-platform web application, hosted on an online server and designed using MVC model architecture. The framework was developed using PHP, CSS3, HTML5, and MySQL for the database. The system was subjected to evaluation by potential users within the institution, and on the whole met with predefined user-specific requirements.
\end{abstract}

Keywords: Web-Based Learning, Collaborative Learning, Distributed Learning Environment

DOI: $10.7176 /$ CEIS/12-2-05

Publication date: April $30^{\text {th }} 2021$

\section{Introduction}

The introduction of the World Wide Web (WWW) has brought significant technological advances in the way humans interact and simplify day to day activities in almost every sphere of life. Since the advent of the Coronavirus (COVID-19), our present-day reality has seen nations brought to a stand-still, placing a higher demand for the need by companies and organizations to bridge the gap in communication and sharing of information with clients and employees using online collaborative platforms. In Nigeria, the federal ministry of education shut down all schools in March 2020 to curtail the spread of the virus (Adeoye, Adanikin \& Adanikin, 2020). In effect, the existing lapses educational institutions were already faced with in terms of a lack of specific technological tools for out-of-the-classroom learning were revealed. As Omang and Angioda (2021) stated, the pandemic has not only affected but has brought to the fore the problems inherent in our education system in the country.

According to the United Nation (2020), the COVID-19 has caused the complex functioning of over 1.6 billion school students globally. Online learning is a product of the integration of technology and traditional ways of learning. Adedoyin, Obariobe, Sanni, and Tahir (2018) give insight into how online learning has grown in popularity and offers numerous benefits over the traditional learning environment.

There are various collaborative systems such as electronic mail, email groups, social media platforms like Facebook groups, and instant messaging apps such as Whatsapp and BBM Adedoyin et al. (2018). However, the need for an online community where teachers and students can share information or collaborate is of great importance presently. On the global scene, Google Classroom has also played an essential role in creating a free collaborative community for institutions globally. Still, as highlighted by Adedoyin et al. (2018), the Google collaborative system comes with limitations.

This paper developed and deployed a web-based collaborative system called "PolyCollab" that bridges these identified gaps in online learning and collaborative platforms. The design and further implementation of this 
system aim to enhance academic collaboration and information sharing between the student and teaching staff of the school of ICT, Auchi Polytechnic, Auchi.

\subsection{Literature Review}

This section provides a background on the concept of collaborative learning and further outlines the adopted framework for the development of our proposed system.

\subsection{Collaborative Learning}

According to (Bicen and Özdamli, 2011), Web-based collaborative learning is viewed as a learning approach that utilizes information retrieved online along with communication technologies to provide a link between student-student, student-teacher, educational foundations, and resources. Zhang and Zhong (2018) also define the term as collaborative learning under a network environment that utilizes computer networks, multimedia, and other related technology. Jianhua and Akahori (2001) categorized web-based collaborative learning environments into five components: peer, learning group, tutor, communication, and web-based learning environment. This collaborative learning can be effectively used to facilitate students' learning performance and enhance their competence of creativity, providing an opportunity for students to work cooperatively with each other and produce projects (Jianhua and Akahori, 2001; Bicen and Özdamli, 2011). In another research, Cheong, Bruno, and Cheong (2012) outlined that collaborative learning centres on a social constructivist approach in which learners are in charge of their learning and engage socially to construct knowledge. For a collaborative learning system to be more effective, it is essential to provide tools to help tutors form learning group (Abnar, Orooji, and Taghiyareh, 2012), promote social interaction to encourage higher-order thinking skills among learners (Cheong, Bruno, and Cheong, 2012). These essential functional requirements may include sharing resources or information (Wu and Hwang, 2014; Adedoyin et al., 2018), allow real-time posting of questions and inquiries which the students can respond to in real-time (Islam, Rahman, Galib, Uddin and Bashir, 2014), send notifications and alerts (Adedoyin et al., 2018). In their research, (Bicen and Özdamli, 2011) determine the competence of teacher candidates towards web-based learning by developing a Likert-type scale called WebBased Collaborative Learning Competence Scale (WBCL-CS). The scale was tested with 300 teacher candidates from Near East University. The research results show that teacher candidates exhibited above the medium level of competence towards web-based collaborative learning. A few constraints about a web-based collaborative system were highlighted by (Cicognani, 2000) which involved interface design and a generic collection of educational material transposed into web compliant formats.

Table 1 shows the uniqueness of the selected author's work in designing and developing a web-based collaborative system.

\begin{tabular}{lll}
\hline S/N & Study & Theoretical Framework \\
\hline 1. & Wu and Hwang(2014) & Analyzing learner's information-searching behaviours. \\
2. & Islam et al. (2014) & ICT based knowledge to learners \\
3. & Adedoyin et al. (2018) & $\begin{array}{l}\text { Functional requirement using model-view-controller (MVC) model } \\
\text { using Laravel framework }\end{array}$ \\
4. & Zhang and Zhong (2018) & $\begin{array}{l}\text { The mobile learning model of collaborative network inquiry based on } \\
\text { big data. }\end{array}$ \\
5. & Cheong, Bruno, and Cheong (2012) & $\begin{array}{l}\text { Mobile application to support social interaction to promote higher- } \\
\text { order thinking skills. }\end{array}$ \\
6. & Abnar, Orooji and Taghiyareh (2012) & Using Genetic Algorithm (GA) to form a mixed group on MOODLE \\
7. & Tiantong and Tongchin (2013) & Stufflebeam's CIPP evaluation model \\
\hline
\end{tabular}

Table 1: Related Literature and its Framework 


\subsection{Architectural Framework of the Web-Based Collaborative Application}

The application development framework adopted for this study is the Laravel framework which functions on an MVC architectural model that uses PHP. The framework was adopted because it provides many enabling features such as dependency injection and server-side rendering.

Components of a typical MVC based web application is depicted in figure 1:

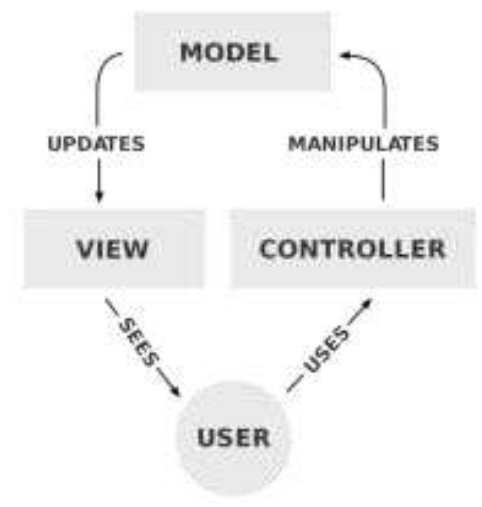

Figure 1: MVC architectural framework

The critical layers of the MVC framework are outlined below:

2.2.1 Data layer (model layer): This layer mainly consists of persistence handling components such as database access components, Data access objects (DAO), query components, Object Rational Mapping (ORM) frameworks, and such. Besides these layers, we also have security components (responsible for authentication and authorization) in the security and utility components to handle cross-cutting concerns.

\subsubsection{Presentation layer (View layer):}

User experience components such as portlets, widgets, pages, User Interface (UI) modules, buttons, and forms are present in this layer. Modern web applications typically use JavaScript components to build the UI modules. The UI modules will mainly render the view portion of the application. View components communicate with the backend through services. Modern web applications use Representational State Transfer (REST) based lightweight services.

\subsubsection{Business layer (Controller layer):}

Controllers do the job of interfacing between Model and View components. They do the regular job of processing all the business logic and incoming requests, manipulating data using the Model component and interacting with the Views to render the final output. For example, the Customer controller will handle all the interactions and inputs from the Customer View and update the database using the Customer Model. The same controller will be used to view the Customer data.

\subsection{Methodology}

This section provided a comprehensive report of how data source, model and database design was captured. The primary data source was information or functional requirements obtained from selected institutions in the country that have already implemented a collaborative system, and the findings were grouped into specific modules.

\subsection{Design}

This section looks into the design of the application's everyday objects, their primary identity, and individual actions to provide a clear visualization of the system's design using Unified Modeling Language.

\subsubsection{Use Case Diagram}

The use case diagram depicted below in the section is a graphical representation of the user's possible interaction with the system. It further shows the different use cases in which every user is involved. As shown in Figure 2, the users are the students, and lecturers/administrators within the School of ICT, Auchi Polytechnic, Auchi. 


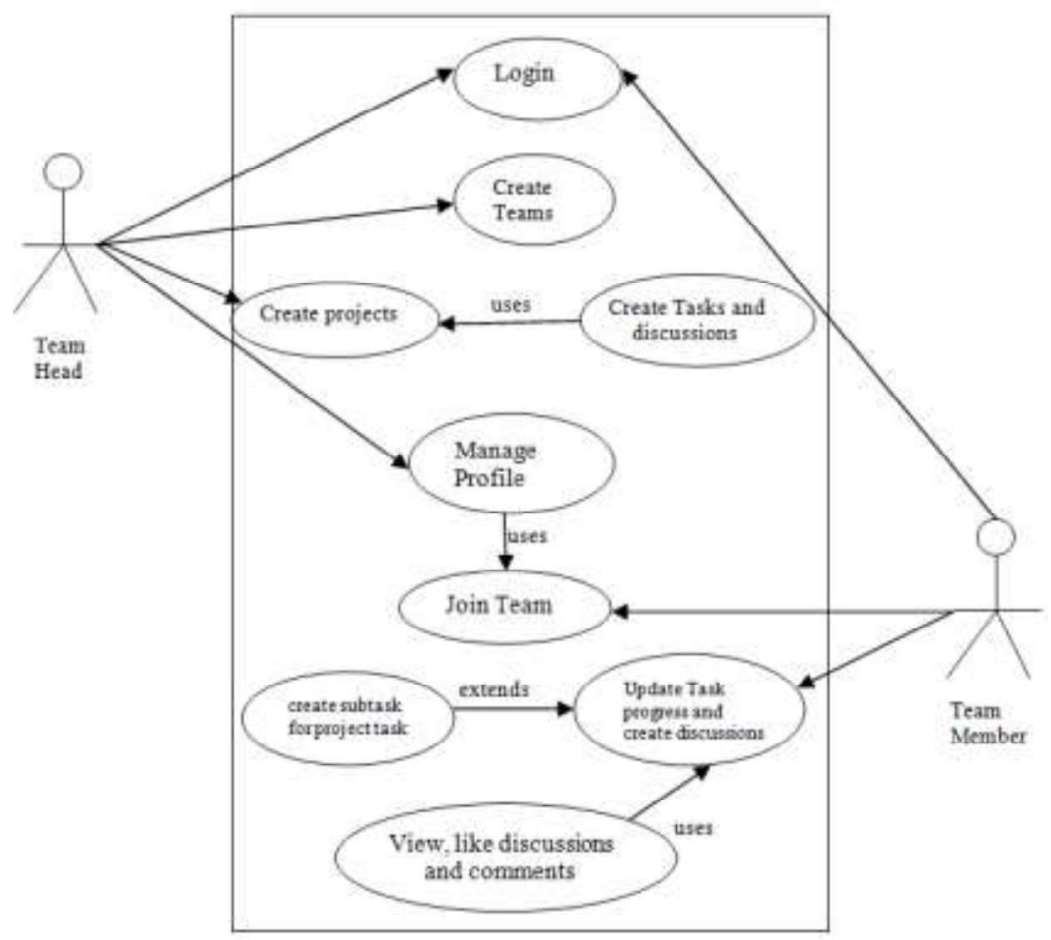

Figure 2: Use Case Diagram of the System

\subsubsection{User Activities}

We use a flow diagram to visualize the user's activities in the proposed system and get an overall picture of the process flow. Flowcharts are a convenient method of representing process and user control flow in a program. The flow chart below provides a pictorial representation of the program's algorithm using relevant symbols to depict the operations and decisions to be carefully followed. The flow of the system, beginning from the input stage, processing, and the final output, is illustrated in Figure 3. Based on the system structure, a team head has adopted administrative privilege, thereby creating a project and adding a team member to a discussion. On the flipside, team members possess more limited access and are have lesser assigned privileges. 


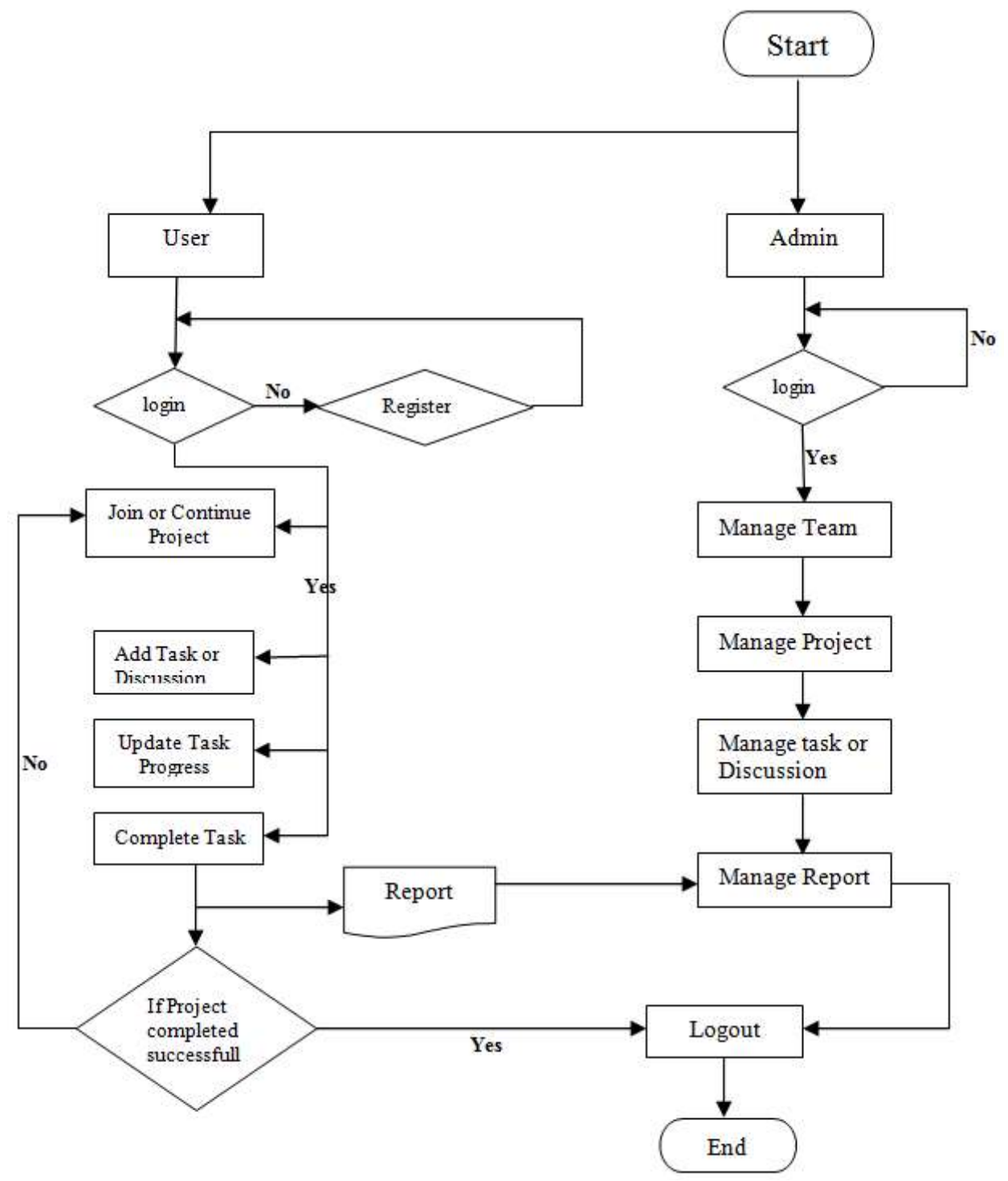

Figure 3: Flow Chart Diagram of the System

\subsubsection{Internal Consistency Test}

Cronbach's alpha is commonly used for the measurement of internal consistency. It is known as a function of the number of test items and the average inter-correlation among the items in a given questionnaire or survey. The formula is:

$$
\alpha=\frac{k}{k-1}\left(1-\frac{\sum s_{i}^{2}}{s_{T}^{2}}\right)
$$

Where:

$$
\begin{aligned}
& k=\text { number of items } \\
& s_{i}^{2}=\text { variance of the } i \text { th item } \\
& s_{\tau}^{2}=\text { variance of the total score formed by summing all the items }
\end{aligned}
$$

An eleven item questionnaire was prepared after students and lecturers had engaged with PolyCollab, a webbased collaborative learning system developed for the school of information and communication technology (ICT), Auchi Polytechnic Auchi. The school of ICT houses four departments: Computer Science, Statistics, Mass Communication, and Office Technology Management (OTM). The questionnaire comprises of two sections; the first section takes bio-information about respondents such as sex, age, status, and department, while 
the second section was adopted from Adedoyin et al. (2018) to obtain the navigability, responsiveness to queries, ease of use, consistency of the application, and the interface presentation. The second section also contains a 4Point Likert Scale for every item. Strongly Disagree $=1$, Disagree $=2$, Agree $=3$, and Strongly Agree $=4$. Forty-eight (48) respondents comprising students and lecturers completed and submitted a valid questionnaire used for evaluation.

\subsection{System Development}

In developing the Polycollab web application, the user interface was designed using PHP, HTML5, and CSS and then further hosted on a web server. MySQL was used at the backend to provide the database requirements for the system. The system was further evaluated to ascertain user perception of the system's functionalities.

\subsection{System Evaluation}

An evaluation of the deployed system was carried out by issuing questionnaires to students and lecturers alike, all of whom had been given a chance to test the Polycollab system. The result was evaluated using IBM SPSS 20 application package. A total of forty-eight (48) valid respondents was captured; thirty-three (33) and thirteen (13) are male and female, respectively. Further analysis shows that twenty-seven (27) male respondents are students while eleven (11) respondents are female. Six (6) males and four (4) females were recorded as the statistics for lecturers. The table shows a cross-tabulation of students and lecturers with their various departments.

\begin{tabular}{lcccccc}
\hline \multirow{2}{*}{ Count } & & \multicolumn{2}{c}{ Department } & Total \\
\cline { 3 - 6 } & & $\begin{array}{c}\text { Computer } \\
\text { Science }\end{array}$ & Statistics & $\begin{array}{c}\text { Mass } \\
\text { Communication }\end{array}$ & OTM & \\
\hline \multirow{2}{*}{ Status } & Student & 17 & 8 & 7 & 6 & 38 \\
& Lecturer & 5 & 1 & 2 & 2 & 10 \\
Total & 22 & 9 & 9 & 8 & 48 \\
\hline
\end{tabular}

Table 2: Cross Tabulation of Student-Lecturer Departmental Relationship

\subsection{Cronbach Alpha Test}

The measurement of reliability or internal consistency of the sub-section of the questionnaire was conducted. The Cronbach's alpha $(\alpha)$ was used as the reliability test for seven (7) items with four (4) Likert-scale, under the PolyCollab system evaluation part of the survey. The Cronbach's alpha $\alpha=0.738$, which is acceptable using the rule of thumb for the results table (Stephen, 2021). Table 2 give the value of every item with its mean and standard deviation.

\begin{tabular}{lrrr}
\hline & Mean & Std. Deviation & N \\
\hline The program provides timely responses to queries & 2.92 & .871 & 48 \\
The program satisfy your expectations in terms of its features & 2.75 & .863 & 48 \\
The user interface is attractive & 3.02 & .758 & 48 \\
The menu items relates to menu titles & 3.35 & .483 & 48 \\
It is easy to navigate through the program & 3.06 & .755 & 48 \\
The user interface easy to understand and user friendly & 2.94 & .697 & 48 \\
The program is easy to start & 3.40 & .536 & 48 \\
\hline
\end{tabular}

Table 2: Item Statistics

Figure 4 shows that over $50 \%$ of users responded positively to all seven (7) items for system evaluation. A total of $22.9 \%$ of the respondents display a pessimistic view regarding program satisfy expectation in terms of features, $85.4 \%$ of the users say the user interface is easy to understand and user friendly, and $97.9 \%$ of the respondents agree to the fact that the program is easy to execute. More details are shown on the graph. 


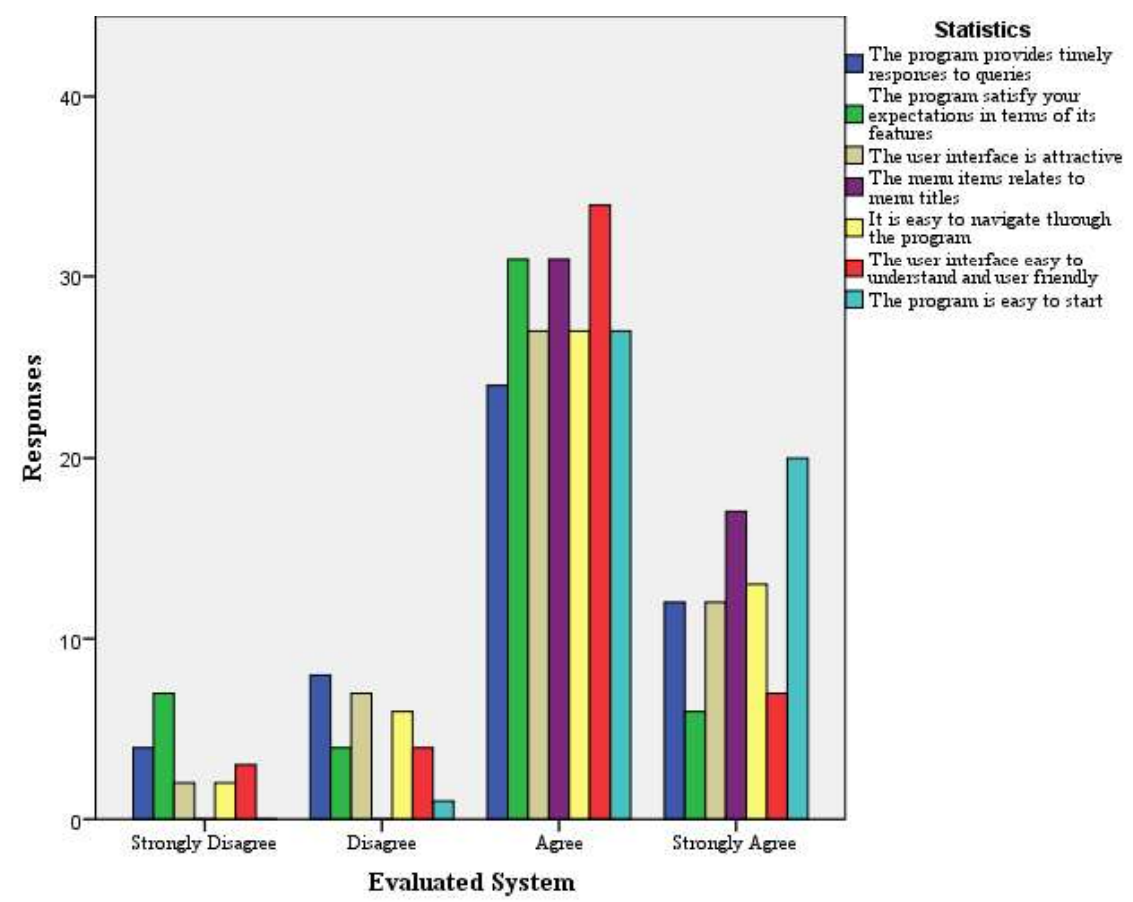

Figure 4: Analysis of the Evaluated System

\section{CONCLUSION}

In this paper, we put forward the framework and designed a cross-platform collaborative web application to bridge the underlying gaps in collaborative learning within the School of ICT, Auchi Polytechnic Auchi. To achieve a fully functional system, we adopted the MVC three-layered architecture for the application and developed its user interface using PHP, CSS, HTML5, MySQL for the database requirements. Furthermore, the working system was evaluated by potential users, and its level of functionality was ascertained by carrying out an analysis of user's perceptions using the Likert scale. Future researchers can add more multimedia features to provide additional interactive capabilities to the web-based collaborative system. Recommended other features may include: Video conferencing, audio recording and voice notes, extended sharing capabilities to blogs and social media.

ACKNOWLEDGEMENT

This work was fully funded by TETFUND grant Batch 7 (TETF/DR\&D/CE/POLY/AUCHI/IBR/2019/VOL.1)

\section{REFERENCES}

Abnar, S., Orooji, F., and Taghiyareh, F. (2012). An Evolutionary Algorithm for Forming Mixed Groups of Learners in Web-Based Collaborative Learning Environments.

Adedoyin, A., Obariobe, O. J., Sanni, A. S. \& Tahir, A. (2018). Development of a Web-Based University Collaborative Tool for Effective Distributed Learning. Afr. J. Comp. \& ICT. 11(3), 33-43

Adeoye, I. A., Adanikin, A. F. \& Adanikin, A. (2020). COVID-19 and E-Learning: Nigeria Tertiary Education System Experience. International Journal of Research and Innovation in Applied Science (IJRIAS), 5(5), 28-31

Bicen, H. \& Özdamli, F. (2011). Validating the instrument of web-based collaborative learning competencies using factor analysis. Procedia Social and Behavioral Sciences, 15 (1) 3921-3926

Cheong, C., Bruno, V. \& Cheong, F. (2012). Designing a Mobile-app-based Collaborative Learning System. Journal of Information Technology Education: Innovations in Practice, 11(2), 97-119 
Cicognani, A. (2000). Concept Mapping as a Collaborative Tool for Enhanced Online Learning. Educational Technology \& Society, 3(3), 150-158

Jianhua, Z. \& Akahori, K. (2001). Web-based collaborative learning methods and strategies in higher education.

Islam T., Rahman S. M. J., Galib M., Uddin K. M. A \& Bashir G. M. M.(2014). Design and Implementation of Web-Based Collaborative Learning Model for ICT Course of College Student in Bangladesh. IJCSMC, 3(1), 393 -400 .

Stephanie, G. (January 12, 2021). Cronbach's Alpha: Simple Definition, Use and Interpretation. StatisticsHowTo.com. https://www.statisticshowto.com/probability-and-statistics/statisticsdefinitions/cronbachs-alpha-spss/

Tiantong, M. \& Tongchin, P. (2013). A Multiple Intelligences Supported Web-based Collaborative Learning Model Using Stufflebeam's CIPP Evaluation Model. International Journal of Humanities and Social Science, $3(7), 157-165$

Omang, T. A., \& Angioda, P. U. (2021). Assessing the Impact COVID-19 Pandemic on the Educational Development of Secondary School Students. Journal of Information and Visualization (JINAV), 2(2), 25-32

United Nation (2020). Policy Brief: Education during COVID-19 and beyond. https://www.un.org/development/desa/dspd/wpcontent/uploads/sites/22/2020/08sg policy brief COVID19 and education august 2020.pdf

Wu, C.H. \& Hwang, G.J. (2014). Collab-Analyzer: An environment for conducting web-based collaborative learning activities and analyzing students' information-searching behaviours. Australasian Journal of Educational Technology, 30(3), 356-374

Zhang, C., \& Zhong, J. (2018). Construction of Mobile Learning Model Based on Network Collaborative Inquiry from Bigdata. MATEC Web of Conferences 232. https://doi.org/10.1051/matecconf/201823201032 